\title{
QUESTÕES ETNOMETODOLÓGICAS PARA PENSAR O DIREITO: UM ESTUDO EMPÍRICO DAS OCUPAÇÕES DOS MOVIMENTOS SOCIAIS DE LUTA PELA MORADIA NA CIDADE DO RIO DE JANEIRO
}

\author{
Ricardo Nery Falbo ${ }^{1}$ \\ Enzo Bello ${ }^{2}$
}

\begin{abstract}
Resumo:
Este artigo reconstrói a realidade dos movimentos sociais urbanos dos sem-teto no Rio de Janeiro no início do século XXI, através de pesquisa empírica que se refere à observação e entrevistas com os ocupantes dos edifícios públicos abandonados na área central da cidade. Do ponto de vista metodológico, a reconstrução teórica da realidade empírica é baseada em ferramentas teóricas e metodológicas e técnicas de pesquisa utilizados no trabalho de campo, de acordo com abordagem etnográfica e etnometodológica de Harold Garfinkel. Do ponto de vista teórico, este trabalho parte da hipótese segundo a qual a condição para conhecer a lei exige que o edifício relação dialética que articula o direito como um produto e o direito como um processo. Baseado no pensamento marxista, esta relação dialética opera com a categoria "cidadania" como uma dimensão da realidade que é central na concepção do movimento sem-teto como uma ferramenta para a produção do direito à moradia em áreas urbanas.
\end{abstract}

Palavras-Chave: movimentos sociais; ocupação urbana; cidadania; cidade; etnometodologia

\section{INTRODUÇÃO}

\section{Plano de Trabalho}

No ano de 2009 foi criado o grupo de pesquisas "Urbanização e movimentos sociais, direitos humanos e Defensoria Pública: para pensar a gestão democrática da cidade do Rio de Janeiro", coordenado pelo Prof. Ricardo Nery Falbo, na linha de pesquisa Direito da Cidade do Programa de Pós-Graduação em Direito da Universidade do Estado do Rio de Janeiro. Na construção e no desenvolvimento do projeto de pesquisa (FALBO, 2010), algumas preocupações fundamentais conferem identidade peculiar à pesquisa: articulação entre

\footnotetext{
${ }^{1}$ Pós-Doutor em Sociologia e Direito pela Universidade Paris 2, Doutor em Sociologia pelo Instituto Universitário de Pesquisas do Rio de Janeiro (IUPERJ) e Professor Adjunto das Faculdades de Direito da Universidade do Estado do Rio de Janeiro (UERJ) e da Universidade Federal do Rio de Janeiro (UFRJ). E-mail: neryfalbo@gmail.com

${ }^{2}$ Doutor em Direito pela Universidade do Estado do Rio de Janeiro (UERJ). Professor Adjunto da Faculdade de Direito e do Programa de Pós-Graduação em Direito Constitucional da Universidade Federal Fluminense (UFF). Professor do Programa de Pós-Graduação em Direito da Universidade de Caxias do Sul (UCS). Consultor da CAPES. E-mail: enzobello@gmail.com
} vol.07, n. 02, Rio de Janeiro, 2014.pp. 683-709 
teoria e prática, visão interdisciplinar do Direito, realização de pesquisa empírica e colaboração entre orientador e orientandos.

Entre os resultados já produzidos constam uma tese de doutorado (BELLO, 2011) e uma dissertação de mestrado (LIMA, 2011), ambas já defendidas, além de artigos publicados e palestras proferidas. Este artigo inserese nesse âmbito e almeja apresentar ao leitor um dos modos pelos quais se tem buscado realizar pesquisas empíricas na área do Direito, enfatizando a sua relevância em termos de inovação metodológica e de ancoragem na realidade. Seus objetivos teóricos e metodológicos constituem a formulação de uma crítica à visão tradicional que comanda o pensamento e as pesquisas do Direito e no Direito.

No prisma teórico, no contexto do limiar do século XXI, propõe-se avançar da concepção tradicional que vislumbra o Direito como um "produto" para uma compreensão do Direito como um "processo", cuja produção envolve necessariamente as dimensões política e social da realidade. Do ponto de vista metodológico, os objetivos dizem respeito à análise dos movimentos sociais e ao papel do trabalho de campo.

A estrutura do artigo é dividida em três partes: empírica, teórico-metodológica e reflexiva, com fundamento na epistemologia das conexões, que preconiza a necessidade de se pensar cada parte em relação com as demais partes.

No primeiro momento, apresentam-se esclarecimentos sobre a definição do objeto de pesquisa e do campo empírico, incluindo extratos das entrevistas realizadas no processo de coleta de dados junto às ocupações de movimentos sociais urbanos sem-teto, com atuação na cidade do Rio de Janeiro. Ademais, são apresentados o instrumental teórico-metodológico e as técnicas de pesquisas utilizados no trabalho de campo, que comporta uma abordagem etnográfica realizada, em conjunto por orientador e de orientando, com base no referencial da etnometodologia de Harold Garfinkel.

$\mathrm{Na}$ segunda etapa, as dimensões teóricas (da sociologia e do direito) são definidas a partir dos temas e/ou problemas revelados no campo, tanto pelas observações dos pesquisados como pelo conteúdo das suas manifestações. O empírico permite pensar diversos conceitos e teorias que integram o pensamento sociológico e podem ser ancorados no direito. A partir da tradição do pensamento marxista, a categoria cidadania foi considerada como dimensão da realidade que define os temas a serem perspectivados teoricamente, diante da sua centralidade na concepção das ocupações dos movimentos sem-teto e como forma de produção do direito à moradia no espaço urbano.

$\mathrm{Na}$ terceira parte, busca-se responder a seguinte pergunta: qual pensamento a realidade das ocupações permite formular? Para tanto, desenvolve-se uma articulação entre os elementos empíricos, metodológicos e teóricos, de modo a se oferecer uma contribuição ao debate sobre as novas formas de produção do Direito na atualidade. 


\section{EMPIRIA: DESCRIÇÃO DO CAMPO DE INVESTIGAÇÃO}

A exclusão socioespacial é um dos principais problemas contemporâneos que afligem o Brasil e a cidade do Rio de Janeiro, e apresenta reflexos socioeconômicos e político-identitários na formação e reestruturação da cidadania. Constata-se que a moradia constitui demanda central na reforma urbana. Os dados estatísticos do IBGE, colhidos no ano de 2006 através da PNAD (Pesquisa Nacional por Amostra de Domicílios), indicam que havia no Brasil um déficit de 7.934.719 moradias, número equivalente a 14,5\% do total de domicílios do país (54.610.413). Na região metropolitana do Rio de Janeiro, o déficit habitacional montava, à época, em 457.839 unidades, o que correspondia a 11,7\% dos domicílios ${ }^{3}$. No Censo de 2010, o IBGE identificou que o número de casas vazias (6,07 milhões) superava o do déficit habitacional do país (5,8 milhões de moradias) ${ }^{4}$.

A cidade do Rio de Janeiro tem um histórico político e social de prática da cidadania em uma estrutura urbana peculiar, que conjuga favelas com bairros nobres, comunidades carentes com condomínios luxuosos e cidades empresariais. Sua população apresenta altos índices de segregação socioespacial, de desigualdades socioeconômicas e de desabrigados, produzindo sujeitos que se notabilizam por suas reivindicações na demanda por moradia 5 .

Merece destaque o fato de a cidade do Rio de Janeiro ter sido escolhida para sediar quatro dos maiores eventos esportivos mundiais: os Jogos Mundiais Militares, em 2011, a Copa do Mundo de futebol, em 2014, e os Jogos Olímpicos e Paraolímpicos, em 2016. Tais eventos têm demandado profundas alterações na sua estrutura urbana. Estas indicações somente foram viáveis porque o poder público (federal, estadual e municipal) comprometeu-se a cumprir as exigências dos cadernos de encargos das respectivas entidades supranacionais Conselho Internacional do Esporte Militar (CISM), Federação Internacional de Futebol Associada (FIFA), Comitê Olímpico Internacional (COI) e Comitê Paraolímpico Internacional (CPI). Esses cadernos de encargos envolvem investimentos (públicos e privados) em diversos setores estruturais, como transportes, segurança, hotelaria, turismo, entre outros.

A política de reforma urbana que está em curso na cidade do Rio de Janeiro tem afetado frontalmente diversas comunidades, que têm sido removidas de seus locais de moradia, sob o pretexto da necessidade de se realizar "obras de modernização".

No âmbito desse conjunto de obras, tem sido implementado o Projeto "Porto Maravilha", destinado à revitalização da área central da capital fluminense, onde se encontram abandonados, há décadas, diversos imóveis e terrenos sem função social. Este é o cenário do objeto real de investigação da presente pesquisa, cujo alvo é a

\footnotetext{
${ }^{3}$ Instituto Nacional de Geografia Estatística, 2006.

${ }^{4}$ BRASIL, 2010.

${ }^{5}$ Esse é um dos motivos pelos quais a cidade do Rio de Janeiro sediou, entre os dias 22 e 26 de março de 2010, o $5^{\circ}$ Fórum Urbano Mundial organizado pela ONU.
} 
dinâmica da formação dos principais movimentos sociais urbanos sem-teto contemporâneos, na cidade do Rio de Janeiro, e sua atuação em meio ao referido processo de reforma urbana. São eles: (i) o Movimento Zumbi dos Palmares e o Movimento Quilombo das Guerreiras (FALBO, 2010, p. 03-06).

\section{As ocupações de movimentos sociais urbanos sem-teto na zona portuária da cidade do Rio de Janeiro}

De acordo com a terminologia oficial adotada pelo Instituto Municipal de Urbanismo Pereira Passos (IPP) e pelo Plano Diretor da Cidade do Rio de Janeiro, o que é considerado área central da capital fluminense compreende as Regiões Administrativas I (área portuária) e II (área central). Na área portuária, que compreende quatro bairros - Caju, Gamboa, Santo Cristo e Saúde -, foram identificados dois imóveis públicos ocupados. O primeiro, de propriedade do Instituto Nacional do Seguro Social (INSS), localizado no número 53 da Avenida Venezuela, Saúde, esteve ocupado de abril de 2005 a fevereiro de 2011. O segundo, de propriedade da Companhia Docas do Rio de Janeiro, localizado no número 49 da Avenida Francisco Bicalho, Santo Cristo, fora ocupado em outubro de 2006.

O caráter público desses prédios diz respeito à natureza jurídica de seus proprietários. O INSS é autarquia federal vinculada ao Ministério da Previdência Social. A Companhia Docas do Rio de Janeiro é sociedade de economia mista vinculada ao Ministério dos Transportes. O abandono que caracteriza os imóveis públicos corresponde ao tempo em que se encontram desativados, segundo informações obtidas a partir de seus ocupantes durante trabalho de campo. $\mathrm{O}$ primeiro estaria abandonado há mais 20 anos, e o segundo há mais de 15 anos.

As ocupações realizadas nesses imóveis são a expressão de movimentos coletivos voltados para o exercício do direito à moradia. Estes movimentos de ocupação urbana são assim autodenominados: movimento Zumbi dos Palmares, que ocupava o prédio do INSS, e movimento Quilombo das Guerreiras, que ocupa o prédio da Companhia das Docas do Rio de Janeiro' ${ }^{6}$

\section{Ocupação Zumbidos Palmares}

Em abril de 2005, mais de 100 pessoas ocuparam o prédio de número 53 da Avenida Venezuela, no centro do Rio de Janeiro. Tendo em vista o estado do imóvel, os ocupantes procederam à limpeza do mesmo e deram início à recuperação das instalações elétricas, sanitárias e hidráulicas. Batizada de Zumbi dos Palmares, a ocupação fora realizada segundo organização e planejamento. Reuniões foram promovidas para discutir, elaborar e aprovar uma espécie de regimento interno e um cadastro de pessoas sem moradia. Os moradores da Ocupação

\footnotetext{
${ }^{6}$ As visitas às ocupações Quilombo das Guerreiras e Zumbi dos Palmares foram realizadas pelo grupo de pesquisas no período de agosto de 2010 a fevereiro de 2011.
} 
reconheceram estar fazendo, na prática, aquilo que os governantes sempre prometeram, mas nunca efetivaram, isto é, transformar prédios públicos abandonados em moradia popular e garantir moradia a famílias de baixa renda com dificuldades em arcar com as despesas de habitação. Em situação de despejo iminente, ou não podendo mais pagar aluguel ou já morando na rua, diversos ocupantes mudaram para o imóvel com todos os seus pertences e nele reconheceram sua moradia definitiva, afirmando "dar vida ao imóvel”.

A ocupação encontrava-se instalada em um prédio de oito andares, habitado apenas até o sexto andar. No terceiro andar foram instaladas a "sala de reuniões", a "sala das crianças" e a biblioteca, além de haver um terraço utilizado para festas. Exatamente como na Ocupação Quilombo das Guerreiras. O interior do prédio apresenta temperatura e ruídos elevados, de modo que os moradores reclamam do calor e do barulho. Os corredores são escuros e há muita fiação elétrica exposta. Os elevadores estavam inutilizados por não haver energia elétrica suficiente. Os moradores movimentavam-se pelo prédio apenas através das escadas.

$\mathrm{Na}$ Ocupação Zumbi dos Palmares, diversos programas sociais foram criados desde a sua fundação, como aulas de alfabetização, reforço escolar, capoeira, fotografia. O movimento de ocupação tem lutado pela sua regularização, com a participação do poder público em projeto que os ocupantes consideram como projeto de moradia popular. Inicialmente, o movimento de ocupação propôs a desapropriação do imóvel por utilidade pública e interesse social, a regularização da situação das famílias ocupantes e cadastradas e a inclusão das famílias no programa Pró-Moradia.

Foi agendado pela Justiça Federal para o dia 15 de janeiro de 2011 o despejo dos moradores da ocupação, para cumprimento da decisão judicial que determinou a reintegração de posse do INSS no imóvel. Diante dessa iminência de despejo, os moradores procuraram diversas autoridades públicas, até que lhes foram apresentadas algumas propostas pela prefeitura municipal: (i) a adesão ao programa "Minha Casa Minha Vida" em conjuntos habitacionais nos bairros de Campo Grande ou Vila Kosmos; (ii) o recebimento de aluguel social; ou (iii) de uma verba indenizatória, fixada em vinte mil reais.

Por motivos diversos, a maioria dos moradores aceitou a "indenização" de vinte mil reais, acreditando que poderia comprar algum espaço para morar no Centro. Houve tentativas por parte dos líderes da Ocupação de explicar ao poder público que o valor oferecido era muito baixo, insuficiente para se comprar uma residência. Mas muitos não entenderam o que eles queriam dizer. As reuniões da ocupação realizadas para se trazer mais conhecimento aos ocupantes foram se esvaziando, pois estes entendiam que o valor ofertado pela prefeitura era 
suficiente. Desse modo, em fevereiro de 2011, o edifício foi completamente esvaziado e entregue ao poder público municipal ${ }^{7}$.

Nas entrevistas realizadas, optou-se por selecionar algumas falas dos militantes Antonia e Juvenal.

Antonia aprendeu a ler em casa, antes de chegar à escola. Trata-se de uma pessoa muito inteligente, que tem um forte sentimento de solidariedade e mostra-se engajada na luta por melhores condições de vida para todos. Considera como ponto central da cidadania a educação, como forma de se proporcionar consciência às pessoas. Mudou-se do Ceará para o Rio de Janeiro em busca de melhores condições de vida. Trabalha informalmente em casa, com artesanato, para poder ficar com as suas três filhas, pois sentiu necessidade. Fez curso de informática na creche e voltou a estudar na escola. Atualmente, ela cursa o ensino fundamental.

Juvenal é casado e tem três filhos. Começou a trabalhar em restaurantes e depois abriu uma marcenaria "em sociedade". Integra a ocupação desde o início, quando foi convidado por sua esposa, que trabalha como costureira. Sua família migrou para o Rio de Janeiro por falta de trabalho em Recife. Inicialmente, sua esposa foi morar com uma irmã na Ocupação Chiquinha Gonzaga, tendo assistido a todas as suas reuniões. Posteriormente, Juvenal foi ao Rio de Janeiro para morar na casa da sua cunhada, até que a Ocupação Zumbi dos Palmares se concretizasse. Buscou seus filhos assim que fixou sua moradia na Zumbi.

Em meio às diversas falas dos entrevistados, alguns trechos foram selecionados em razão da sua importância em relação a determinados conceitos e práticas da ocupação enquanto estratégia de criação e efetivação de direitos. Confiram-se, respectivamente, as manifestações de Antonia e Juvenal:

\begin{abstract}
Me vejo cidadã assim: foi uma luta, não comprei esse espaço, mas lutei, melhorei, limpei. A luta da Ocupação Zumbi dos Palmares é por morar no centro da cidade, não necessariamente neste prédio. [A ocupação foi uma] luta como se tivesse comprado o apartamento e que a luta continua. Cidadania é trabalhar de alguma forma, conquistar, valorizar, não pensar no individual, é participar. A partir de quando se conhece o direito, começa a lutar. Ele pode estar escrito, mas tem que buscar. Tem que tomar atitude para esse direito acontecer. A educação é muito importante, a leitura; sem leitura passa despercebido; ler, conversar, contato; se não, não enxerga, não entende. Cabe ao Estado, à Defensoria Pública dar o que a gente precisa. Movimento social precisa da associação, precisa de estudo, de união. [Com o fim da ocupação], vou viajar pra ficar um mês com meus pais. Eles nem conhecem as minhas filhas. Estou fora do Ceara há 17 anos. Se eu ver (sic) que lá tem tudo de bom pras minhas filhas, eu fico; senão, eu volto. Me preocupo demais com as minhas filhas.

Tá escrito na Constituição direito à moradia, mas por que não no centro? Tem que levar [a gente] para longe (...). No início, é novo, é tudo bonito, depois é um caos, não passa mais coleta de lixo. Não diz muita coisa [o direito escrito na Constituição]. Prédio é construído com problemas. Não tem manutenção. Material de terceira. Povo não consegue fazer obra porque é caro. Defesa civil interdita tudo. É só para mostrar que fez. É possível resolver a moradia. Ainda tão (sic) fazendo as casas do Livramento, mas depois o pessoal se esquece, é
\end{abstract}

\footnotetext{
${ }^{7} \mathrm{O}$ processo de extinção da Ocupação Zumbi dos Palmares ocorreu de modo paulatino e apresentou uma série de nuances. Por limitação de espaço, optou-se por mencionar neste artigo somente os elementos objetivos e cronológicos. Para mais detalhes, confira-se: BELLO, 2011, p. 356-367.
} 
pobre. A obra demora demais. Você passa lá, têm dois lá virando massa. Ia ficar pronta em um ano e meio. Vai levar dez anos pra ficar pronta. A obra demora demais para outras coisas ir (sic) mais rápido. Mas não querem terminar por interesse deles. Fazer hotel para turista é mais vantajoso. Investimento com nossos impostos. Quando compra qualquer coisa, a gente paga imposto; camelô também paga imposto. As reuniōes na época pré-ocupação eram semanais e duraram nove meses. Quando a Zumbi se organizou e iniciou a ocupação, a Chiquinha existia há apenas um ano. O objetivo era impedir que aproveitadores permanecessem na ocupação. É necessário comparecer a todas elas para poder pertencer a alguma ocupação, para impedir que aproveitadores vendam seus espaços. São profissionais da ocupação. O espaço é para quem precisa dele para morar. Isto é pior que a prática do Estado, porque parece especulação imobiliária. [Com a indenização do Estado] não dá para comprar nada aqui; se pagar aluguel, acaba em um ano e a gente tá na rua de novo (...). Qualquer aluguel aqui tá $\mathrm{R} \$ 600,00, \mathrm{R} \$ 700,00$.

Em uma segunda etapa, passou-se à investigação da Ocupação Quilombo das Guerreiras.

\section{Ocupação Quilombo das Guerreiras}

Em outubro de 2006, mais de 150 famílias ocuparam o prédio de número 49 da Avenida Francisco Bicalho, no centro do Rio de Janeiro. Denominada de Quilombo das Guerreiras, a Ocupação fora formada por trabalhadores, homens e mulheres, que protestavam contra a falta de política habitacional voltada à população de baixa renda. Os ocupantes reclamavam ainda da falta de dignidade quanto às condições de moradia em que eles se encontravam nos lugares em que moravam antes da ocupação. Os ocupantes constituíam famílias que antes moravam nas ruas ou em abrigos, cortiços ou barracos.

Nos arredores do terreno da ocupação situam-se a Rodoviária Novo Rio, alguns depósitos abandonados e duas quadras de escolas de samba. O local é cercado por grandes avenidas e tem intenso movimento de tráfego, simultaneamente ao exíguo número de pedestres, mesmo durante o dia. No período noturno a região fica erma e mostra-se perigosa, mas Roberto mencionou que, segundo depoimentos dos próprios policiais militares que patrulham a área, houve queda de cerca de 70\% no número de assaltos na região após o início da ocupação, pois começou a haver circulação de pessoas (os moradores da ocupação) em ruas antes desertas, chegando e saindo para o trabalho, nos mais diversos horários.

A ocupação encontra-se instalada em um prédio de seis andares, edificado no interior de um terreno de grandes extensões (não foi possível checar a metragem). Segundo relatos dos entrevistados, trata-se de imóvel de propriedade "pública mista" (União Federal e Estado do Rio de Janeiro). O prédio conta com enorme terreno ao lado (denominado "estacionamento") e aos fundos (depósito abandonado, não utilizado pelos moradores). Como local de moradia, os ocupantes utilizam somente o prédio, até o quinto andar. No terceiro andar foram instaladas a "sala de reuniões", a "sala das crianças" e a biblioteca, além de haver um terraço que é utilizado para festas. $\mathrm{O}$ interior do prédio apresenta temperatura e ruídos elevados, de modo que os moradores reclamam do 
calor e do barulho. Os corredores são escuros e há muita fiação elétrica exposta. Os elevadores estão inutilizados por não haver energia elétrica suficiente. Os moradores movimentam-se pelo prédio apenas através das escadas.

A formação da ocupação envolveu um longo processo. A sua constituição não foi fruto de uma ação espontânea, mas de um conjunto de atos premeditados. Houve uma preparação prévia que contou com a realização de diversas reuniões entre os interessados em formar um movimento de ocupação. Trata-se de pessoas que viviam ou nas ruas ou em locais distantes, que se reuniram sob o intento comum de obtenção de uma moradia digna na região central da cidade. Esses sujeitos debateram diversos assuntos, principalmente quem integraria o movimento, qual seria o local escolhido para a ocupação, como seria feito o ato de tomada do prédio, como seriam instaladas as famílias, entre outros.

Nas entrevistas realizadas, destacaram-se as figuras de Janine e Roberto, que se mostraram mais solícitos e articulados para as conversas. Ambos desenvolvem todas as suas atividades na região central da cidade.

Janine se mostrou uma pessoa consciente, com facilidade em se expressar e bom vocabulário. Completou o Ensino Médio e chegou a ingressar na Faculdade de Administração da UERJ, tendo abandonado o curso por conta do nascimento de seu primeiro filho. Militou ativamente no movimento estudantil secundarista, mas jamais foi filiada a qualquer partido político. Participou do movimento "Fora Collor", sem integrar organizações políticas, tendo atuado politicamente na Escola João Alfredo, quando chegou a invadir estações do metrô para protestar contra Collor.

Roberto é uma pessoa muito bem articulada, com facilidade de se expressar e tem bom vocabulário. Completou o Ensino Médio e é servidor público federal do Ministério da Aeronáutica. Desenvolve todas as suas atividades (trabalho, estudo e lazer) na região central da cidade, ressaltando a facilidade de transportes e a proximidade de instituições como escolas e hospitais em relação ao local da ocupação.

Em meio às diversas falas dos entrevistados, alguns trechos foram selecionados em razão da sua importância em relação a determinados conceitos e práticas da ocupação enquanto estratégia de criação e efetivação de direitos. Confiram-se, respectivamente, as manifestações de Janine e Roberto:

Cidadania é buscar os meus direitos, que o Estado tem que reconhecer. Ele tem que ser pressionado para dar moradia. A vida aqui é coletiva. As tarefas são divididas. A coletividade tem um regimento interno, que fica na parede da sala de reuniões. É uma espécie de 10 mandamentos. Aqui eles [autoridades públicas] quase não aparecem. Eles propõem outras formas de moradia, mas não serve. Mas aqui já temos nosso jeito, nosso espaço. [Mudar para a Zona Oeste?], não, Deus me livre! A nossa vida tá aqui. Nada de aluguel social. Morar no centro fica mais barato e mais perto.

A condição para participar do movimento de ocupação de local novo era comparecer diariamente às reuniões realizadas na Chiquinha Gonzaga. $\mathrm{O}$ objetivo é a conscientização social e política, informação, procedimentos da próxima ocupação. Os candidatos têm que assistir e participar, levando mantimentos para fazer a ocupação. Ninguém sabia onde e quando ia ocupar. Só no próprio dia da ocupação e no momento de fazer a mudança. Nem na hora de sair da reunião para o local da invasão se sabe para onde vai: é só quando chegar 
lá, que descobre: 'é aqui!'. Quem ocupava ficava sem sair de dentro do prédio, no mínimo, uma semana, para evitar a remoção e garantir a invasão. Aqui não tem liderança, nem por antiguidade, nem por nenhum outro critério. Nem coordenação. Só quando houve a ocupação, para dirigir o movimento. Aqui tem o sistema de votos. Hoje ainda têm 30 integrantes do coletivo que participam da ocupação desde o início. Mas antiguidade aqui não é posto. A convivência aqui é difícil. Já houve roubo e expulsão. Cheguei a ir ao Ministério das Cidades, em Brasília. Não consegui chegar ao ministro, mas fui bem recebido. Não consegui resolver o problema [de saneamento]. Provavelmente não vamos ficar aqui nesse prédio. Vamos ser remanejados. Mas sem luta não há vitória. Não quero sair daqui para nenhum outro lugar. Temos constituído raízes. É preciso manter a história da luta viva. Tem as vantagens do ponto. Paz, o centro da cidade, onde tem trabalho para todos. Já tinha até casa pronta pra nós em Sepetiba e Santa Cruz. Sem desmerecer esses lugares, mas a fonte de renda tá no Centro. O objetivo aqui é um só, a moradia. Viemos pra cá com a ideia de permanecer. Quando eu vim para a ocupação, eu morava na casa de meus pais, mas eu tinha que ser um cidadão completo, participar da questão social.

O material selecionado das quatro entrevistas realizadas junto às duas ocupações está projetado sobre os tópicos seguintes, em especial o de $n^{\circ} 5$, no qual a dimensão empírica será cotejada com as perspectivas metodológica e teórica.

\section{METODOLOGIA: A ETNOMETODOLOGIA COMO ESTRATÉGIA PARA A PESQUISA EMPIRICA EM DIREITO}

\section{Etnometodologia: questões teóricas}

"As atividades práticas, as circunstâncias práticas e o raciocínio sociológico prático, como temas de estudos empíricos" (GARFINKEL, 1992, p. 01). É desta forma que Harold Garfinkel define o campo de pesquisa da etnometodologia, corrente sociológica americana por ele fundada no final dos anos 60 na Califórnia. "Atribuindo às atividades da vida cotidiana a mesma atenção que habitualmente se presta aos acontecimentos extraordinários" (GARFINKEL, 1992), Garfinkel procura compreendê-las como fenômenos de direito pleno.

O autor de Studies in Ethnomethodology constrói um modelo de pesquisa empírica referido ao mundo concreto da vida cotidiana de seus agentes. Em contextos sociais tão distintos quão diversos, a compreensão das ações sociais torna-se dependente da análise do raciocínio prático desenvolvido pelos agentes e dos procedimentos por eles utilizados para alcançar seus fins e atribuir sentido às suas práticas sociais. "Os procedimentos utilizados pelos agentes para se chegar ao conhecimento do senso comum no curso da interação não diferem dos procedimentos utilizados pelo pesquisador para se chegar ao conhecimento científico" (GARFINKEL, 1992).

A distinção que ele faz entre conhecimento de senso comum e conhecimento científico não contempla, no entanto, as rupturas epistemológicas bachelardianas entre objeto real e objeto teórico, que importam distinção e separação entre agente social e cientista social quanto aos métodos por eles utilizados para alcançar a 
compreensão das ações sociais. Ao reconhecer que os métodos utilizados pelo agente social não se distinguem daqueles utilizados pelo pesquisador, Garfinkel também reconhece a ideia de que a compreensão das ações sociais no mundo concreto da vida cotidiana não constitui atividade exclusiva do cientista social. No entanto, a inteligibilidade e a visibilidade do mundo concreto dependem da linguagem da vida cotidiana empregada neste mundo. "É sobre esta forma de linguagem do senso comum, a linguagem do cotidiano, que o pesquisador social deve debruçar-se, porque é ela a base para o entendimento das ações sociais práticas" (GARFINKEL, 1992).

O pensamento de Harold Garfinkel se constitui como ofensiva crítica da sociologia clássica, principalmente da tradição representada pela sociologia de Talcott Parsons. Preocupado com o problema da ordem social na sociedade capitalista de sua época - e com as causas da desorganização social nos Estados Unidos do entre guerras -, Parsons procura explicar o funcionamento das estruturas sociais e os processos de racionalização das ações sociais. Para o autor de Ensayos de teoría sociológica, "além de constituir a 'espinha dorsal' de orientação de ação de todos os sistemas sociais existentes, as instituições definem as condutas legitimamente esperadas e desejadas" (PARSONS, 1967, p. 207).

Neste sentido, a coesão social depende da regulação institucional dos agentes sociais, cujas condutas desviantes possíveis devem ser normativamente reprimidas como condição da cooperação social efetiva. A consequência que daí decorre é a situação de subordinação e de redução da racionalidade e da ação dos agentes sociais a padrões normativos considerados como social e legitimamente institucionalizados. Desta forma, afastando-se do universo racional de base utilitarista, Parsons afirma que "a sociologia não pode ser confundida com a psicologia nem com a economia" (PARSONS, 1967, p. 97). Afinal, os fenômenos e os problemas sociológicos possuem suas próprias especificidades, e a psicologia e a economia reduzem sistemas mais gerais de ação a tipos específicos de sistemas sociais.

Submetidos às normas sociais que determinam suas ações no mundo da vida cotidiana, os agentes sociais são, então, considerados como destituídos de reflexividade e, por conseguinte, vistos como incapazes de descrever sua relação com a realidade social em geral e com o mundo das normas sociais em particular. Afinal, para Parsons, "as motivações dos atores sociais são integradas em modelos normativos que regulam as condutas e as apreciações recíprocas. Assim se explica a estabilidade da ordem social e sua reprodução em cada encontro entre os indivíduos" (COULON, 1995, p. 10).

Para Parsons, a investigação sociológica se interessa pela compreensão e pela análise dos sistemas sociais, definidos como "constituintes do sistema mais geral da ação e dos processos de ação recíproca de pequenos e grandes agregados sociais (PARSONS, 1967, p. 16). A articulação que ele faz entre os dois tipos de agregados (pequenos e grandes) the permite afirmar não haver razão para o uso de uma única perspectiva teórica na sociologia. Ao integrar as abordagens sociológicas de níveis micro e macro no campo da teoria sociológica 
contemporânea, o modelo teórico e analítico de Parsons define para a pesquisa sociológica um campo de investigação onde o conhecimento geral é construído com base em casos particulares específicos.

\section{Etnometodologia: questões conceituais}

\section{Membro}

Como afirma Garfinkel (1970, p. 339):

A noção de membro é o fundo do problema. Não utilizamos este termo para nos referirmos a uma pessoa. Ele diz respeito propriamente ao uso da linguagem comum. Nós o entendemos da seguinte forma: entendemos que a pessoa, ao falar uma linguagem natural, está comprometida de alguma maneira com a produção e apresentação objetivas do conhecimento de senso comum quanto a seus assuntos cotidianos enquanto fenômenos observáveis e relatáveis.

Neste sentido, a noção de membro não está diretamente referida à relação que articula pessoa e grupo social, senão ao uso da linguagem comum, que, no entanto, supõe a filiação a um grupo ou instituição.

Com uma frequência e uma insistência universais, os membros empregam fórmulas destinadas a remediar o caráter indexical de suas expressões e, mais concretamente, procuram substituir as expressões indexicais por expressões objetivas (Garfinkel, Sacks, p. 339).

Rejeitando assim a concepção parsoniana de membro pertencente a uma comunidade, bem como a ideia de indivíduos vivendo organizados de forma coletiva, Garfinkel reconhece que as pessoas particulares e os indivíduos são "aspectos observáveis de atividades ordinárias" (JULES-ROSETTE, 1985, p.39). Assim, um membro é uma pessoa que realiza atividades práticas, que integra circunstâncias práticas, que possui raciocínio sociológico prático, que emprega procedimentos específicos e conhecimento de senso comum e que assim é capaz de criar os mecanismos de adaptação que atribuem sentido ao mundo social em que vive.

\section{$\underline{\text { Realização prática }}$}

"Os fatos sociais são as realizações dos membros" (GARFINKEL e SACKS, 1970, p. 353). A noção de "realização dos membros" adotada pela etnometodologia supõe a produção de práticas contínuas pelos agentes sociais. Consequentemente, a realidade social, associada à ideia de ordem, estabilidade e equilíbrio, não é vista nem como "dado" nem como "coisa", e sim como processo, permanente e contínuo.

Neste sentido, normas e regras não são consideradas como estruturas significativas estáveis, preexistentes e independentes das interações sociais, às quais aderem os atores sociais. Elas são construções práticas e circunstanciais que definem e revelam os raciocínios sociais práticos e os métodos utilizados pelos agentes sociais em suas interações sociais, cuja realização depende da interpretação do mundo segundo aqueles mesmos raciocínios e métodos e do uso da linguagem que fazem os agentes sociais na comunicação do conhecimento de sentido comum. 


\section{Reflexividade}

"[Os membros] consideram evidente esta reflexividade, mas reconhecem, demonstram e tornam observável para cada um dos outros membros o caráter racional de suas práticas concretas - o que quer dizer ocasionais -, considerando esta reflexividade como uma condição inalterável e inevitável de suas investigações" (GARFINKEL, p. 9). O autor de Studies in ethnomethodology distingue entre reflexividade e reflexão quanto às práticas dos agentes sociais. As práticas reflexivas dos agentes não significam que eles tenham consciência da reflexividade destas mesmas práticas.

"Para os membros da sociedade, o conhecimento de senso comum dos fatos sociais está institucionalizado como conhecimento do mundo real" (GARFINKEL, p. 55). Este conhecimento possui duas propriedades. Primeira: descrever a sociedade real para seus membros. Segunda: definir as características da sociedade real como sendo produzidas pela conformidade motivada das pessoas à semelhança de uma profecia que se realiza. (GARFINKEL, p. 55).

A reflexividade pode ser definida como a propriedade das práticas dos agentes sociais que permite descrever e que constitui determinado quadro social. "As descrições do social se convertem, no momento de expressá-las, em partes constitutivas daquilo que descrevem" (COULON, p. 44). O pressuposto da reflexividade é que "as atividades realizadas pelos membros para produzir e manejar as situações de sua vida organizada de todos os dias são idênticas aos procedimentos utilizados para tornar descritíveis ditas situações" (GARFINKEL, p. 1).

\section{"Accountability"}

"Os estudos etnometodológicos analisam as atividades cotidianas dos membros como métodos que tornam as próprias atividades visivelmente racionais e capazes serem referidas a todos os fins práticos, isto é, descritíveis, enquanto organização ordinária das atividades de todos os dias" (GARFINKEL, prólogo). A "accountability" das atividades cotidianas e de suas circunstâncias traduz a reflexividade de que é constituída toda prática social, isto é, a capacidade de descrição que constitui o próprio quadro social "accountable". Referida à reflexividade, a "accountability" supõe ainda a racionalidade ou inteligibilidade das práticas sociais.

O caráter cotidiano e rotineiro da vida social pode revelar a personalidade dos agentes sociais através da "accountability", com a qual a personalidade dos agentes pode confundir-se. Esta situação configura a hipótese de reificação quando a "accountability" é normalmente considerada como fato natural. Esta situação decorre "das disposições pelas quais a sociedade oculta de seus membros suas atividades de organização e os conduz assim a apreender seus rasgos como objetos determinados e independentes" (GARFINKEL, p. 182). 


\section{"Indexabilidade"}

Garfinkel parte da ideia segundo a qual os discursos práticos se caracterizam pela "indexabilidade”, isto é, a significação dos mesmos depende do contexto em que eles existem (GARFINKEL, SACKS, p. 339). Isto significa dizer que o sentido das expressões "não pode ser decidido por um ouvinte que não saiba ou presuma algo necessariamente sobre a biografia e os objetivos daquele que emprega a expressão, das circunstâncias do enunciado, do curso anterior da conversação ou da relação particular da interação atual ou potencial que existe entre aquele que fala e aquele que ouve" (GARFINKEL, p. 4).

Decorre daí que todo significado da linguagem - bem como das demais formas simbólicas (gestos, regras, ações) - é sempre compreendido de forma particular porque referido à situação particular. Para Garfinkel, a "indexabilidade" é propriedade também da linguagem natural, cujo sentido depende das condições de uso e de enunciação. O caráter plástico e dinâmico das circunstâncias da vida social - prática, cotidiana e rotineira - define a incompletude da "indexabilidade" dos discursos práticos e a rejeição do caráter objetivo, natural e geral da linguagem comum ou científica.

\section{Etnometodologia: questões metodológicas}

O objeto de estudo da etnometodologia são os métodos que constituem "o raciocínio sociológico prático", isto é, os "etnométodos", e a etnometodologia é a ciência que estuda estes métodos. Do ponto de vista metodológico, a questão é quanto à abordagem dos etnométodos e de seus estudos. "Os estudos etnometodológicos não estão destinados a trazer ou a demonstrar corretivos (...). Embora estejam destinados à preparação de manuais sobre os métodos sociológicos, eles não são de nenhum modo suplementos dos processos tipificados, são apenas distintos" (GARFINKEL, prólogo). Apesar de seu caráter crítico, a etnometodologia não procura nem corrigir a sociologia tradicional nem produzir nova metodologia. A este respeito, Garfinkel define sua orientação metodológica nos seguintes termos: "Nosso trabalho não consiste em modificar, elaborar, contribuir, detalhar, dividir, explicar, sustentar a relação com o raciocínio sociológico profissional. Sentimos apenas indiferença por estas tarefas" (GARFINKEL; SACKS, 1970, p. 345). A “indiferença metodológica” define a visão que orienta a investigação etnometodológica. "As pessoas que fazem estudos etnometodológicos podem preocupar-se tanto com o raciocínio sociológico profissional como das práticas do raciocínio jurídico, do raciocínio da conversação, do raciocínio adivinhatório ou psiquiátrico, etc." (GARFINKEL; SACKS, 1979, p. $346)$.

Diante da falta de originalidade quanto às técnicas e aos métodos de investigação, a etnometodologia recorre principalmente aos métodos qualitativos da etnografia e da sociologia, tais como as formas de observação, 
dos atores e dos campos, que exigem do investigador a familiaridade com o ambiente da pesquisa e que Garfinkel chama de "unique adequacy" (JULES-ROSETTE, 1985).

\section{Etnometodologia: questões técnicas}

Partindo do princípio segundo o qual a etnometodologia está interessada em descobrir os procedimentos que os membros utilizam para chegar ao conhecimento do senso comum no curso de suas interações e assim organizar sua vida social cotidiana, comum, a realização de conversas e de entrevistas constituem igualmente técnicas de coleta de material no âmbito dos trabalhos etnometodológicos. Se o modo como os membros de um grupo social utilizam os discursos e as expressões da vida cotidiana permite determinar a posição de suas experiências e de suas atividades (CICOUREL, 1977, p. 60), ele também permite definir o fundamento do raciocínio sociológico prático.

A análise da conversação e da fala (MYERS, 2002) é técnica que permite alcançar esse objetivo. Segundo esta técnica, os dados obtidos com a realização de entrevistas e a observação de atores e campos devem ser remetidos às suas situações particulares de interações específicas (MYERS, 2002, p. 271). Os dados devem ser considerados como atos de fala e de conversação. Como tais, os dados não considerados como possuindo nenhuma propriedade ou status especial que justifique a separação ou a hierarquização dos mesmos (MYERS, 2002, p. 272). Assim analisados, os dados permitem identificar as categorias de pensamento dos membros de um grupo social investigados, bem como a importância destas categorias para os mesmos e as suas opiniões. Os membros da investigação definem o referencial da análise. Segundo Myers, a análise dos investigados não pode ser realizada de forma independente do investigador e das circunstâncias da interação da pesquisa. A técnica da análise da conversação e da fala se volta para o conhecimento do modo de organização das interações pelos participantes da pesquisa (MYERS, 2002, p. 272) e permite pensar a pesquisa e o papel do pesquisador na sua realização.

Myers reconhece que a técnica da análise da conversação produz quantidade suficiente de dados que justifica que as transcrições dos mesmos sejam tratadas como dados brutos. Como a análise da conversação depende da qualidade das transcrições dos dados, ele pensa a organização da pesquisa de acordo com os seguintes elementos práticos: planejamento (escolha de tema para guiar a entrevista), registro (a qualidade da gravação define a qualidade da transcrição), transcrição (a riqueza da análise depende do detalhamento da transcrição), atribuição (saber identificar o autor de cada fala), análise (a análise depende da audição da gravação e da leitura da transcrição) e relatório (a forma ideal consistindo em apresentar trechos da fita como demonstração de um argumento). 
Um dos problemas metodológicos apontados por Myers quanto à análise de conversação diz respeito à generalização, isto é, a relação da amostra com o conjunto mais amplo da sociedade. Segundo ele, os grupos sociais investigados não são representativos da sociedade de modo geral. Eles se caracterizam pelas particularidades que justificam a seleção e a investigação dos mesmos quanto às questões teóricas formuladas. Daí a necessidade metodológica de evitar toda generalização. Outro problema metodológico diz respeito à identidade dos investigados que participam de outros grupos sociais. Segundo Myers, os pesquisadores devem analisar apenas os elementos de identidade que aparecem nas falas dos investigados.

\section{TEORIA: A CIDADE COMO ESPAÇO DA CIDADANIA ATIVA PRATICADA PELOS MOVIMENTOS SOCIAIS}

A cidade constitui-se como um modelo conceitual multifacetário, pois expressa um espaço geopolítico e um ator político (CASTELLIS, Borja, 1996, p. 152-166). Jordi Borja e Zaida Muxí apresentam como novo marco a compreensão do espaço público como conjunção entre cidade e cidadania. Considerada por Borja e Muxí (2003, p. 103-104) como composta por três elementos - urbs, civitas e polis -, a cidade é definida como:

el producto físico, político y cultural complejo, europeo y mediterraneo y también americano y asiático, que hemos caracterizado en nuestra cultura, en nuestro imaginario y en nuestros valores como concentración de población y actividades, mezcla social y funcional, capacidad de autogobierno y ámbito de identificación simbólica y de participación cívica. ${ }^{8}$

Diante do seu atual quadro de crise de dissolução, fragmentação e privatização, os autores compreendem que a reinvenção da "cidade cidadã" representa o advento de uma nova cultura política, na qual a prática cidadã dos movimentos sociais pode transformar demandas ilegais ou alegais em novos direitos urbanos de cidadania, como por exemplo: ao lugar e à moradia, à identidade coletiva dentro da cidade, à conversão da cidade marginal ou ilegal em cidade de cidadania, à ilegalidade, ao emprego e ao salário cidadão, e o de todos os residentes em uma cidade a ter o mesmo status político-jurídico de cidadão (BORJA, MUXÍ, 2003, p. 124-129).

Existe uma correspondência entre os modelos de cidade formulados pelas políticas de urbanização e as práticas de cidadania desenvolvidas no seu âmbito. No período contemporâneo, preconiza-se um ideal globalizado de cidade que expressa elementos da tradição política liberal, voltada à promoção da impessoalidade e homogeneidade no espaço público, pautada por políticas de urbanização de conotação empresarial (SASSEN, 1998). Assim, embora haja o reconhecimento de uma importante e renovada gama de direitos de cidadania, estes persistem negligenciados na prática pelo poder público, que, paralelamente, instituem normatividades legitimadoras de posturas de exclusões e desigualdades sociais.

\footnotetext{
${ }^{8}$ BORJA; MUXÍ, 2003, p. 41.
} 
Nesse cenário, observa-se a produção de um novo fenômeno que caracteriza a prática da cidadania nas cidades. Trata-se das ocupações como estratégia de ação política e concretização dos direitos de cidadania por iniciativa dos próprios cidadãos. As ocupações urbanas envolvem um agrupamento de sujeitos em torno de um objetivo comum, qual seja, a promoção do acesso à moradia de pessoas alijadas da questão habitacional. Esses sujeitos se organizam de forma estruturada e, a partir da centralidade dessa bandeira, constituem-se na forma de movimentos sociais com projetos políticos pautados por ideologias distintas, ora mais abrangentes em termos de transformação social ("movimentos de massas"), ora em sentido mais estrito ligado apenas à satisfação de demandas específicas ("movimentos pontuais").

As ocupações surgem como possíveis soluções quanto aos impasses que envolvem a base concreta e real da concepção de cidade que tem sido adotada no Brasil, que, na prática, não inclui os novos movimentos sociais no processo de produção da reurbanização. A concepção teórica de cidade e a prática da produção da cidade na atualidade - emblematicamente, no Rio de Janeiro - mostram-se aptas à descrição de uma realidade hostil à cidadania (teoria) e ao cidadão (prática) quando se verificam as reiteradas remoções dos movimentos de ocupações através de ações truculentas do poder público. Em suma, pode-se afirmar que a exclusão quanto ao direito à moradia, do ponto de vista da passividade do status de direitos, tem produzido os novos movimentos sociais enquanto modelo e fenômeno, fomentado a criatividade social em termos de práticas cidadãs.

Em sentido genérico, a expressão "movimentos sociais" já era utilizada com referência às mobilizações políticas dos atores sociais no século XIX (protagonizadas por coletividades como os sindicatos operários e os primeiros partidos políticos). Estes sujeitos reivindicavam a inclusão social de segmentos marginalizados pela ordem político-jurídica, de modo a lhes conferir o reconhecimento de direitos como a liberdade, a igualdade e o sufrágio universal. Nesse sentido, historiadores marxianos como Eric Hobsbawm (2000) e Eduard Thompson (2002) consideram como movimentos sociais o cartismo e o owenismo, entre outros.

Em sentido especificamente sociológico, a nomenclatura "movimentos sociais" assume um significado mais peculiar nas últimas décadas do século XX, para designar a emergência de novos atores político-sociais, representados por um formato de organizações populares diverso dos modelos clássicos dos partidos políticos e sindicatos. Trata-se, em linhas gerais, de movimentos coletivos heterogêneos, constituídos no âmbito da sociedade civil, que reivindicam autonomia e independência perante o Estado, além de formularem demandas sociais diversificadas e amparadas em valores - como pluralismo e diversidade - diferentes daqueles anteriormente propugnados. Os principais movimentos sociais da atualidade relacionam-se a uma variedade de temas como etnia, gênero, sexualidade, ecologia, serviços públicos e sociais, entre outros.

A partir das contribuições de Gramsci (2007, p. 244), mostra-se evidente que um fortalecimento da sociedade civil, em conjunção com uma atuação perante o Estado (sociedade política), somente é viável a partir 
da atualização dos sujeitos políticos que compõem esse campo de disputas. Desse modo, ao invés de serem vistos como sucessores dos partidos políticos e sindicatos, os movimentos sociais devem ser agregados aos processos políticos, que, cada vez mais, tornam-se longos e duradouros, demandando uma ação continuada na disputa pela hegemonia nas estruturas de poder (BELLO, 2011, p. 151).

Rotulados e conhecidos como "novos movimentos sociais", esses atores políticos surgem no contexto de uma crise aguda da democracia representativa e de intensas transformações no sistema produtivo capitalista. Suas principais inovações consistem nas alternativas que oferecem aos instrumentos tradicionais da política institucional, como uma ênfase maior na ação direta (protestos e reivindicações) e uma atuação em novos cenários (ruas, estradas e praças).

A riqueza de elementos oriundos da experiência cotidiana da prática política dos "novos movimentos sociais" tem produzido inovações que exercem reflexos em diversos campos do conhecimento. No que tange ao presente trabalho, serão exploradas apenas as vertentes relativas à política, à sociologia e ao direito.

Obviamente, as primeiras tentativas de sistematização teórica dos movimentos sociais ocorreram no âmbito da sociologia, destacando-se algumas correntes de pensamento da sociologia empirista estadunidense e da escola marxista europeia, além de figuras como Claus Offe, Alberto Melucci e Alain Touraine. A partir dos seus desenvolvimentos teóricos sobre o tema, uma plêiade de seguidores passou a trabalhar com a temática dos movimentos sociais, utilizando uma ou outra abordagem. Portanto, são múltiplos os conceitos atribuídos.

Adotando-se a premissa que não existe um conceito único, capaz de abranger todas as suas características, tem-se como marco inicial, para a compreensão geral acerca dos movimentos sociais, a sistematização proposta por Maria da Glória Gohn:

Movimentos sociais são ações sociopolíticas construídas por atores sociais coletivos pertencentes a diferentes classes e camadas sociais, articuladas em certos cenários da conjuntura socioeconômica e política de um país, criando um campo político de força social na sociedade civil. As ações se estruturam a partir de repertórios criados sobre temas e problemas em conflitos, litígios e disputas vivenciados pelo grupo na sociedade. As ações desenvolvem um processo social e político-cultural que cria uma identidade coletiva para o movimento, a partir dos interesses em comum. Esta identidade é amalgamada pela força do princípio da solidariedade e construída a partir da base referencial de valores culturais e políticos compartilhados pelo grupo, em espaços coletivos não-institucionalizados. Os movimentos geram uma série de inovações nas esferas pública (estatal e não-estatal) e privada; participam direta ou indiretamente da luta política de um país, e contribuem para o desenvolvimento e a transformação da sociedade civil e política. Estas contribuições são observadas quando se realizam análises de períodos de média ou longa duração histórica, nos se observam os ciclos de protestos delineados. Os movimentos participam portanto da mudança social histórica de um país e o caráter das transformações geradas poderá ser tanto progressista como conservador ou reacionário, dependendo das forças sociopolíticas a que estão articulados, em suas densas redes; e dos projetos políticos que constroem com suas ações. Eles têm como base de suporte entidades e organizações da sociedade civil e política, 
com agendas de atuação construídas ao redor de demandas socioeconômicas ou políticoculturais que abrangem as problemáticas conflituosas da sociedade onde atuam. ${ }^{9}$

Resta claro que os "novos movimentos sociais" protagonizam uma renovação no conceito e na prática da cidadania, desbravando horizontes no cenário contemporâneo de política mundial. Suas esferas de atuação segmentam-se conforme as bandeiras que empunham e com os sujeitos aos quais se dirigem. Há diversas ordens de movimentos sociais - locais, regionais, nacionais, transnacionais e globais -, que, em muitos casos, atuam de forma coordenada no tratamento de suas demandas. Nessa linha de raciocínio, outro aspecto territorial que define o campo de atuação dos movimentos sociais é o da compreensão da realidade espacial.

Apesar de os primeiros movimentos sociais terem surgido em incipientes cidades industriais inglesas do século XIX, nos chamados países periféricos o berço desses sujeitos é a zona rural, pois seu processo produtivo foi calcado no setor primário da economia. Consequentemente, os maiores conflitos sociais produziram-se no campo, em torno da questão do acesso à terra. Somente ao longo do século XX, na senda do progressivo processo de urbanização da maioria dos países do globo, constituíram-se em larga escala movimentos sociais urbanos, afetos a questões típicas da realidade do espaço das cidades, como serviços públicos de saúde e transporte. São exemplos de movimentos sociais urbanos o "movimento pela meia entrada", o "movimento dos sem-teto", entre outros.

Sob a denominação "movimentos sociais urbanos", são aqui compreendidos os grupos sociais ligados a conflitos e interesses especificamente das cidades, articulando dialeticamente a perspectiva da luta de classes (distribuição socioeconômica) com as novas demandas identitárias (reconhecimento), considerando a centralidade do espaço urbano como locus fundamental das disputas políticas no final do século XX e início do século XXI. Portanto, assumem especificidades estratégicas e comportamentais em relação à vida no campo.

Entre os diversos movimentos sociais urbanos da atualidade, destacam-se aqueles voltados à satisfação de uma demanda referencial, o reconhecimento e a efetivação do direito à moradia. A moradia figura como elemento central na formação moderna do urbano e nas demandas por direitos nas cidades, e, principalmente, como grande catalisador dos conflitos urbanos contemporâneos.

A justificativa pela abordagem da questão habitacional é coerente com o seu papel enquanto elemento catalisador dos conflitos urbanos contemporâneos e, consequentemente, representação das demandas urbanas de cidadania. Em âmbito nacional, têm-se como exemplos de movimentos sociais urbanos em prol da luta pela moradia o Movimento dos Trabalhadores Sem-Teto (MTST), a Frente Internacionalista dos Sem-Teto (FIST) e o MTD (Movimento dos Trabalhadores Desempregados).

No contexto específico da cidade do Rio de Janeiro, os primeiros movimentos sociais urbanos surgiram na forma de associações de moradores nas favelas e, posteriormente, passaram a constituir coletivos de 
abrangência maior, voltados para a questão urbana, caracterizados como movimentos de ocupações, os quais são objeto da presente investigação.

\section{ANÁLISE TEÓRICO-METODOLÓGICA}

No sentido do preconizado pela etnometodologia, a investigação empírica proporciona a obtenção de dados brutos, que sempre dependerão de contextualização, tanto para a análise metodológica quanto para a análise teórica.

A partir do material empírico reunido na pesquisa de campo, nas condições acima apresentadas, tem-se um quadro delineado quanto à situação em que se encontram os sujeitos entrevistados. Os trechos selecionados das quatro entrevistas nas duas ocupações apontam para alguns conceitos fundamentais que são trabalhados nas ciências sociais e, recentemente, têm ganhado espaço na área do direito: práxis, alienação, reificação, fetichismo, ativismo político, entre outros.

No entanto, quanto às atividades e às circunstâncias práticas referentes às ocupações, as entrevistas revelam mais do que categorias de interesse teórico e científico. Elas ilustram a ideia de membro definida segundo o uso da linguagem comum. Neste sentido, por exemplo, o direito é compreendido não como realidade-coisadevida, e sim realidade-processo-de-luta. É essa linguagem comum do direito que, além de conferir sentido à vida do quotidiano rotineiro das ocupações e de garantir alcançar seus objetivos, traduz e confere visibilidade concreta às ocupações e seus membros. Afinal, as ocupações e seus membros existem como dimensões observáveis de suas próprias atividades concretas, ordinárias e quotidianas. Porém, o modo como os membros utilizaram o uso da linguagem do direito permitira determinar a posição de suas experiências e de suas atividades, enfim, suas interações em suas vidas rotineiras.

Como realização prática produzida pelas ocupações e seus membros, a realidade social - e também jurídica - é produção prática e contínua. É a possibilidade de descrever essa realidade prática, produzida pelos membros das ocupações através da linguagem comum revelada pelas entrevistas - e também através da observação empírica realizada quando das entrevistas -, que permite afirmar a reflexividade e a "accountability" que caracterizam e constituem as práticas quotidianas e suas circunstâncias.

Neste sentido, a própria significação prática dos discursos dos membros das ocupações só pode ser compreendida segundo o próprio contexto da realização prática das entrevistas e de suas circunstâncias, o que permite retomar o conceito de indexabilidade. Este resultado exige também a familiaridade e o conhecimento do campo de investigação, das ocupações e de seus membros. Os membros que observaram os pesquisadores foram também por eles observados quando das entrevistas, da mesma forma que as circunstâncias práticas das entrevistas foram igualmente observadas. Assim, na fala dos membros, as ocupações se constituíam e funcionavam 
de forma coletiva, sem líder. Porém, nenhuma entrevista fora realizada senão mediante agendamento prévio com aquele que acompanhara a realização de todas as entrevistas. A recorrência à linguagem do coletivo, em oposição ao individual, permite supor uma estratégia defensiva das ocupações contra os atos do poder público que supõem a individualização de seus destinatários, tais como as intimações cumpridas pelos oficiais de justiça.

Ainda quanto ao contexto, as condições das ocupações (poluição sonora, situação de remoção iminente) não garantiram nem a possibilidade de gravação das entrevistas nem o cumprimento do planejado para as mesmas, com entrevistas estruturadas.

Em razão da relevância temática e da limitação de espaço neste artigo, optou-se por trabalhar com as categorias cidade, cidadania e movimentos sociais. Estas expressam o espaço, a prática e a forma de organização dos sujeitos entrevistados, que estão inseridos no âmago de um processo de conflitos sociais na luta pela moradia enquanto meio de reivindicação e efetivação do direito.

A partir de uma dimensão dialética dos conceitos, referidos a realidades que expressam relações que articulam dinamicamente processos e produtos, pode-se vislumbrar uma nova forma de se conceber o direito no alvorecer do século XXI. Não mais apenas como algo pronto e acabado, que pode ser materializado apenas através das instituições oficiais do Estado. Mas como um conjunto de elementos permanentemente constituídos e revigorados pelos seus destinatários, os próprios cidadãos, no cenário das vidas cotidianas e consideradas as necessidades materiais que thes movem política e existencialmente.

A chave da etnometodologia tem um importante ponto de contato com o pensamento marxiano, vez que apresenta uma prática de desmistificação e desobjetivação de categorias reificadas e comportamentos naturalizados e naturalizadores. Nessa vereda, destacam-se as observações dos entrevistados no sentido das limitações da atuação estatal em prol da efetivação dos direitos fundamentais dos cidadãos, que findam diferenciados de acordo com as posições que ocupam no processo produtivo, inclusive territorialmente.

As falas dos entrevistados são explícitas em relação à clivagem teórica atinente ao conceito de cidadania, em especial quanto às suas vertentes passiva e ativa. Eles demonstram ter discernimento sobre o papel da educação na conscientização do ser humano e compreendem que a mobilização política e social surge a partir das necessidades materiais de cada um. Há uma referência direta ao direito escrito como fonte de reivindicação quando declaram conhecerem a constituição federal. Mais ainda quando se afirma que não basta a existência de uma norma escrita para que se garanta a sua efetividade e que se atenda as demandas sociais. Existe todo um processo complexo e multifacetário por detrás, que muitas vezes emperra a consecução dos direitos fundamentais. Portanto, agregar energias e lutar, através de uma atuação coletiva, para se superar os entraves criados pelas forças econômicas e estatais. 
A respeito dos movimentos sociais, tem-se clara uma acepção associativa que reúne indivíduos marginalizados pelo poder público em razão de uma necessidade material específica, a moradia, que se desdobra em outros temas de relevância. Entre seus componentes, tem-se uma maioria ampla de trabalhadores informais, sujeitos desprestigiados pelo direito em razão da sua inexistência de vínculo laboral nos moldes legais. $\mathrm{Na}$ constituição, na organização e na convivência diária dos cidadãos que compõem esses movimentos sociais vislumbra-se um senso de coletividade aliado ao papel individual de cada um nessa comunidade. Tanto é que os próprios militantes fazem uma autocrítica em relação aos companheiros desordeiros que cometem desvios.

A cidade representa o grande fator de inovação na prática da cidadania, em muito revigorada desde o surgimento e a difusão dos movimentos sociais. $\mathrm{O}$ espaço urbano desponta como um grande território a ser explorado e disputado pelos grupos sociais. O centro da cidade indica um grau mais elevado de acessibilidade a serviços públicos essenciais, de modo que as reivindicações dos movimentos sem-teto priorizam a ocupação de terrenos abandonados, sem função social, localizados nas regiões mais antigas das grandes metrópoles, tradicionalmente tidas como desvalorizadas tanto pelo Estado como pelo mercado imobiliário. Todavia, como mencionado pelos entrevistados, existe muitos fatores além da norma escrita que impedem a sua viabilidade material, como por exemplos as prioridades eleitas pelos governantes na destinação de recursos públicos e na realização de obras, que privilegiam determinados setores da sociedade em detrimentos de outros.

\section{CONCLUSÕES}

Diante do exposto, considera-se respondida a pergunta apresentada na introdução - qual pensamento a realidade das ocupações permite formular? - da seguinte maneira. Ao longo da elaboração deste estudo, mostrouse constante a preocupação em se captar, traduzir e formular o que a etnometodologia denomina "raciocínio sociológico", que orienta no cotidiano as condutas que ele próprio traduz. Isto é, o pensamento - ou o conhecimento de senso comum prático - que orienta as pessoas individual e coletivamente. Logo, buscou-se formular o pensamento que as ocupações também "formulam".

Analisando as dimensões do prático e do empírico através do teórico-(etno) metodológico, é possível afirmar qual o pensamento que as ocupações formulam - e que os pesquisadores traduzem sob a forma de "raciocínio sociológico prático": é o pensamento através da linguagem do direito-como-processo-de-luta, e não como-coisa-devida.

É importante ressaltar, através das falas dos integrantes das ocupações, que nem todos percebem e se orientam pela luta pelo direito à moradia da mesma forma, o que demonstra a existência de dissensões e até mesmo conflitos dentro das ocupações. Isto explica condutas tais como a expulsão de militantes que cometem desvios, como a venda de espaços (apartamentos) nas ocupações. Mesmo quando afirmam ser positivo morar nas 
ocupações, os ocupantes também reconhecem as individualidades que comprometem a sua ordem interna e o seu funcionamento. Logo, nem todos reconhecem o direito da mesma forma; afinal, eles próprios também não se reconhecem da mesma maneira. Em suma, não se pode deixar uma imagem "ascética" das ocupações, com a afirmação de que o raciocínio sociológico prático é o mesmo e único para todos.

Assim, evidenciam-se alguns temas fundamentais a servirem de contributos para a constituição e ampliação de uma plataforma de produção de pesquisas empíricas na área do direito. O empírico e o teórico caracterizam-se como manifestação de uma relação específica que articula direito e sociedade, mostrando-se viável e pertinente a discussão teórica acerca dos movimentos sociais e das novas práticas de cidadania (ocupação). Nessa linha, tem-se a manifestação de outra concepção acerca do direito, a partir de uma visão não institucional calcada no cotidiano dos cidadãos e nas suas ações na busca de suprir suas necessidades materiais, pois a coesão social não depende da regulação jurídica e institucional dos agentes sociais, da forma como pretende a tradição jurídica. A realidade social - e também jurídica - constitui um processo de produção prática, contínua e permanente, realizada pelos agentes sociais.

Assim, cabe ressaltar a importância da incorporação e intensificação da produção de pesquisas empíricas na área do Direito, em especial em virtude da principal inovação que oferece ao ambiente jurídico: acesso a dados fornecidos pela realidade que não são captáveis através dos instrumentos tradicionais (doutrina e jurisprudência). Cabe afirmar que a não captação decorre, precisamente, da falta de contextualização destes instrumentos e de que eles são usados também de forma excludente em relação a outras fenomenologias. Na conjuntura contemporânea, mostra-se cada vez importante dar voz ativa aos membros que integram a realidade e constroem o direito no cotidiano, no contexto em que tais vozes são ouvidas e produzidas, assim como o próprio direito.

\title{
ETHNOMETHODOLOGICAL QUESTIONS TO THINK STRAIGHT LAW: AN EMPIRICAL STUDY OF OCCUPATIONS OF SOCIAL MOVEMENTS THE STRUGGLE FOR HOUSING IN THE CITY OF RIO DE JANEIRO
}

\begin{abstract}
:
This article reconstructs the reality of urban social movements of the homeless in Rio de Janeiro in the early twenty-first century through empirical research referred to the observation and the interviews with the occupants of abandoned public buildings in the central area of the city. From the methodological point of view, the theoretical reconstruction of empirical reality is grounded in the theoretical and methodological tools and research techniques used in the field work in accordance with ethnographic and ethnomethodological approach by Harold Garfinkel. From the theoretical point of view, this work assumes the hypothesis according to which the condition for knowing the law requires the dialectical relationship building that articulates the right as a product and the right as a process. Based on Marxist thought, this dialectical relationship operates with the category
\end{abstract}


"citizenship" as a dimension of the reality that is central in the conception of the homeless movement as a tool for the production of the right to housing in urban areas.

Keywords: Social movement; Urban occupation; Citizenship; City; Ethnomethodology

\section{REFERENCIAS BIBLIOGRÁFICAS}

BELLO, Enzo. Teoria dialética da cidadania: política e direito na atuação dos movimentos sociais urbanos de ocupação na cidade do Rio de Janeiro. Tese de doutorado. Rio de Janeiro. Universidade do Estado do Rio de Janeiro, 2011.

BORJA, Jordi; MUXÍ, Zaida. El espacio público: ciudad y ciudadanía. Barcelona: Electa, 2003.

BRASIL. Número de casas vazias supera déficit habitacional do país, indica Censo 2010. Brasília, 2010. Disponível na internet em: http://www.brasil.gov.br/noticias/arquivos/2010/12/13/numero-de-casas-vazias-superadeficit-habitacional-do-pais-indica-censo-2010.

CASTELLS, Manuel; BORJA, Jordi. As cidades como atores políticos. In: Novos Estudos Cebrap, São Paulo, nº 45, julho/1996, p. 152-166.

CICOUREL, Aaron. A Etnometodologia. In: BIRBAUM, Pierre; CHAZEL, Francois. Teoria Sociológica. São Paulo: Hucitec/Edusp, 1977.

COULON, Alain. Etnometodologia. Petrópolis: Vozes, 1995.

FALBO, Ricardo Nery et alli. Projeto de pesquisa - Urbanização e movimentos sociais, direitos humanos e defensoria pública: para pensar a gestão democrática da cidade do Rio de Janeiro. Rio de Janeiro, mimeo, 2010, 27 p.

GARFINKEL, Harold. Studies in Ethnomethodology. New York: Blackwell Pub, 1992.

GARFINKEL, Harold; SACKS, Harvey. Theoretical Sociology, Perspectives and Developments. New York: Appleton-Century Crofts, 1970.

GOHN, Maria da Glória. Teorias dos movimentos sociais: paradigmas clássicos e contemporâneos. 5ª ed., São Paulo: Loyola, 2006.

GRAMSCI, Antonio. Cadernos do Cárcere. Vol. 3. Maquiavel. Notas sobre o Estado e a política. Rio de Janeiro: Civilização Brasileira, 2007.

HOBSBAWM, Eric. Os trabalhadores: estudo sobre a história do operariado. 2a ed., São Paulo: Paz e Terra, 2000.

INSTITUTO NACIONAL DE GEOGRAFIA E ESTATÍSTICA. Síntese de indicadores sociais de 2006. Brasília, 2006. Disponível na internet em: http://www.ibge.gov.br/home/estatistica/ população/ condicaodevida/indicadoresminimos/sinteseindicsociais2006/indic_sociais2006.pdf

JULES-ROSETTE, B. Sociétés. nº 5, vol. 1, sept., Paris: 1985. 
LIMA, Monique Falcão. Poder Judiciário: espaço público de integração entre direito e política através dos movimentos sociais na cidade do Rio de Janeiro. Dissertação de mestrado. Rio de Janeiro. Universidade do Estado do Rio de Janeiro, 2011.

MYERS, Greg. Análise da Conversação e da Fala. In: BAUER, Martin W; GASKELL, George (Orgs.). Pesquisa qualitativa com texto, imagem e som; um manual prático. Petrópolis: Vozes, 2002.

PARSONS, Talcott. Ensayos de teoría sociológica. Buenos Aires: Paidós, 1967.

SASSEN, Saskia. As cidades na economia mundial. São Paulo: Nobel, 1998.

THOMPSON, Eduard. P. A formação da classe operária inglesa. III - A força dos trabalhadores. $3^{a}$ ed., Rio de Janeiro: Paz e Terra, 1987. (Impresso em 2002)

Trabalho enviado em 30 de maio de 2014.

Aceito em 30 de maio de 2014. 